\title{
Experimental Study of Parallel Plate Fin Heat Sinks with and without Perforation on Circular Pin Fins between the Plate Fins
}

\author{
Rahul R. Sonawane* and D. D. Palande \\ ${ }^{1}$ Department of Mechanical Engineering, Savitribai Phule Pune University, MCOERC Nashik, India
}

Accepted 15 June 2016, Available online 20 June 2016, Special Issue-5 (June 2016)

\begin{abstract}
It is very important to enhance the heat transfer rate and ensure the better cooling of electronic devices. The fined surface is most commonly used to dissipate heat quickly to the surrounding flowing fluid. Experiment is carried out to investigate heat transfer rate in natural convection of parallel plate fin heat sink with circular pin fins placed between the plate fins. The firstly parallel plate heat sink consists of without perforated circular pin fin and its performance is compared with perforated circular pin fin. The height of circular pin fin is taken as $50 \mathrm{~mm}, 35 \mathrm{~mm}, 25$ $\mathrm{mm}$ respectively for both cases. Further the number of perforation on pin fin increases and its effect on heat transfer rate is also examined. The result shows that, parallel plate fin heat sink with perforated circular pin fins gives more heat transfer than without perforated circular pin fins. In above three cases, it is observed that circular pin fin at 25 $\mathrm{mm}$ height shows better heat transfer than other two heights. The increase in number of perforation on each pin fin increases heat transfer rate.
\end{abstract}

Keywords: Parallel plate fin Heat sink, Circular pin fins, Perforation, Heat transfer rate.

\section{Introduction}

Electronic systems during their operation generate heat. This heat has to be dissipated quickly to surrounding atmosphere otherwise it may increase the temperature of the electronic components. It is very necessary to maintain the operating temperatures of electronics components at a safe and satisfactory level. Heat sink is used to dissipate the heat rapidly to surrounding fluid.

(Dong-Kwon Kim, et al, 2009) compared plate and pin-fin heat sinks subjected to an impinging flow for different flow rates and channel widths. They found that optimized pin-fin heat sinks shows lower thermal resistances when dimensionless pumping power is small and the dimensionless length of heat sinks is large. (Abdullah $\mathrm{H}$, et al, 2009) compared solid and perforated horizontal rectangular fin in natural convection by using finite element technique. They observed that, perforated horizontal rectangular fin has more heat transfer and less weight compared to equivalent solid fins. (E.A.M.Elshafei, 2010) compared solid circular pin fins with perforated circular pin fins in staggered arrangement in natural convection. They also tested performance of heat sink for two different orientations and observed that, the perforated pin fins gives better heat transfer in sideward arrangement than upward arrangement. (Monoj Baruah, et al, 2011)

*Corresponding author: Rahul R. Sonawane investigated the performance of elliptical pin fins which arranged in a staggered manner. Three perforations were provided on elliptical pin fins and its performance compared with corresponding solid elliptical pin fin. They have observed that, the three perforations on elliptical pin fins gives more heat transfer. (Anupam Dewan, et al, 2011) also studied heat transfer from an array of circular pin fins and observed that, the perforation on pin fin reduces the weight and the cost of pin fin. (Ji-Jinn Foo, et al, 2012) studied heat transfer with perforated pin fin by varying the number of horizontal perforation and the diameters horizontal and vertical perforation on pin fin. They found that, the perforated pin fin array gives more heat transfer than the corresponding solid pins. (G. Ganesh Kumar, 2013) observed that the variation of local temperature difference is more for hollow perforated pin fin compared to that the solid perforated pin fin.

(Ali Shakir Baqir, et al, 2014) studied staggered perforated pin fin array in a rectangular channel. They have compared HLV (horizontal, vertical, lateral) perforated pin fin with HV perforated and solid pin fin. They observed that the HLV perforated pin fin shows higher heat transfer than HV perforated and solid pin fin heat sink.

(Saurabh D. Bahadure, and G. D. Gosavi, 2014) carried out the thermal performance of a pin fin heat sink. In experiment, they varied the material of pin fin such as Aluminum, Copper and mild steel and number 
of perforation on pin fin from 1 to 3 respectively. They found that the average heat transfer coefficient is higher for three perforations compared to solid, single, and two perforations respectively.

(Murtadha Ahmed and Abdul Jabbar N. Khalifa, 2014) compared solid and perforated square pin fin heat sinks in natural convection. They found that the temperature drop across perforated pin fin was less than that of solid pin fins. (Vishvas S. Choure, 2015) studied heat transfer enhancement from perforated pin fin in staggered arrangement. The number of Perforation varied from one to five and diameter of perforation from 3 to 5 respectively. They have observed that the Nusselt number increases with increase in number of perforation and diameter of perforation.

In present study, experiment is carried out to investigate heat transfer rate in natural convection of parallel plate fin heat sink with circular pin fins placed between the plate fins. The firstly parallel plate heat sink consists of without perforated circular pin fin and its performance is compared with perforated circular pin fin. The variation of height of circular pin fin and effect of number perforation on heat transfer coefficient is also examined.

\section{Experimental Setup}

\subsection{Heat Sinks Dimensions}

The dimensions of the setup are given as below;

Base plate $=133 \mathrm{~mm} \times 155 \mathrm{~mm}$.

Height of parallel plate fin $=50 \mathrm{~mm}$.

Thickness of parallel plate fin $=3 \mathrm{~mm}$.

Height of pin fin $=50 \mathrm{~mm}, 35 \mathrm{~mm}, 25 \mathrm{~mm}$ respectively.

Diameter of circular pin fin $=8 \mathrm{~mm}$.

Diameter of perforation $=3 \mathrm{~mm}$.

No. of perforation $=1,2$.

\subsection{Experimental setup and procedure}

The experimental set-up primarily consists of wooden rectangular chamber and digital control panel as shown in Fig.1. The rectangular wooden chamber is made in such way that it is open from top and bottom portion while all other sides are closed. The three sides of chamber are closed with plywood and front side of chamber has removable glass sheet so as to replace different types of pins. Inside the chamber the concrete block supported with the help of wooden block. The heater plate is placed on the concrete block to supply heat input to heat sink model. The test set up was kept in controlled room to establish free convection over pin fin arrays.

The parallel plate pin fin heat sink is mounted on concrete block with the help of four screws to tight pin fin array over heater plate. Thermocouples are sandwiched between heater plate and heat sink at different locations to measure the temperature of base of fin. Thus, air gap between heater plate and pin fin array is consider to be negligible. Also, heat loss through excess portion to the pin fin arrays was assumed negligible for comparative analysis.

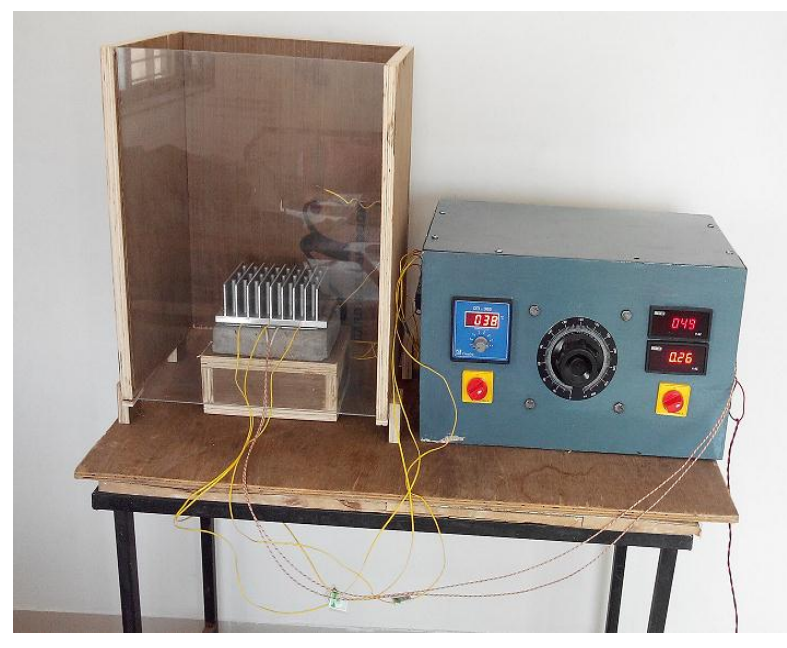

Fig.1 Experimental Set-up

The plate fin configurations are produced by milling operation on rectangular block. The plate fin arrays were produced from rectangular block with dimensions $138 \times 188 \times 63 \mathrm{~mm}$. Fins were kept integral with the base plate of thickness $10 \mathrm{~mm}$ while, fin thickness was kept constant as $3 \mathrm{~mm}$. The circular pin has $8 \mathrm{~mm}$ diameter and they are placed between the parallel plate fins. Geometry of pin fin array is shown in the Fig.3. The fin material was selected as aluminum 6063 alloy because of its high thermal conductivity, $\mathrm{k}$ $202 \mathrm{~W} / \mathrm{m} . \mathrm{K}$ at $20^{\circ}$, low emissivity $\left(\sim 0.2\right.$ at $\left.20^{\circ}\right)$.

For the experimentation, electrical power supplied to heater and heat input is adjusted with the help of dimmer stat. The dimmer stat can be used to change the heat input such as $20 \mathrm{~W}, 40 \mathrm{~W}, 60 \mathrm{~W}, 80 \mathrm{~W}$ and $100 \mathrm{~W}$. As heater goes on heating, the temperature of fin start rising which is sensed by the thermocouple and indicated on digital temperature indicator. The base-plate temperatures of fin arrays are measured by $\mathrm{T} 1, \mathrm{~T} 2, \mathrm{~T} 3, \mathrm{~T} 4$ and T5 thermocouples and ambient temperature by T6 thermocouples. The average of these five readings is taken as the base plate temperature. The heater input is kept constant for different set of heat sink model and noted the reading.

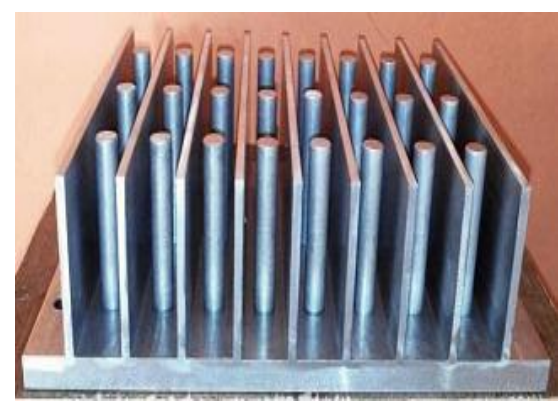

Fig.2(a) Height of pin $50 \mathrm{~mm}$ without perforation 


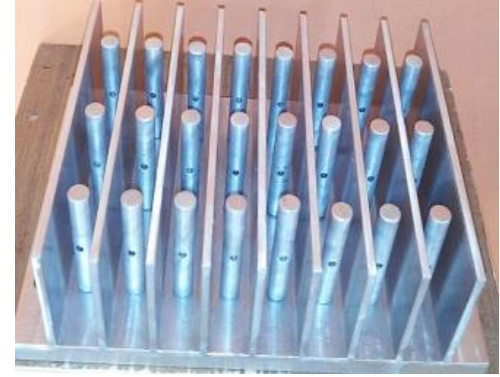

Fig.2(b) Height of pin $50 \mathrm{~mm}$ with single perforation

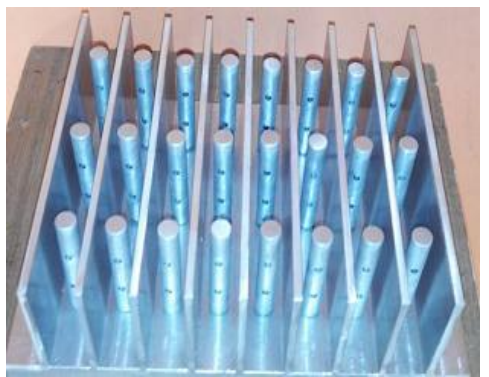

Fig.2(c) Height of pin $50 \mathrm{~mm}$ with double perforation

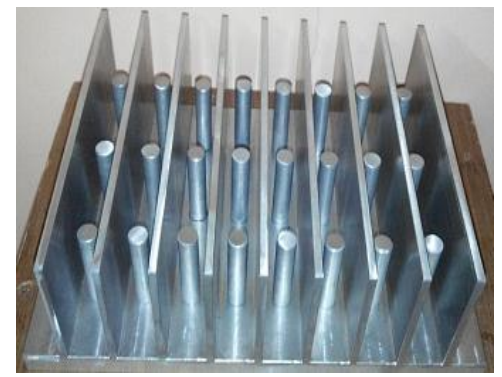

Fig.2(d) Height of pin $35 \mathrm{~mm}$ without perforation

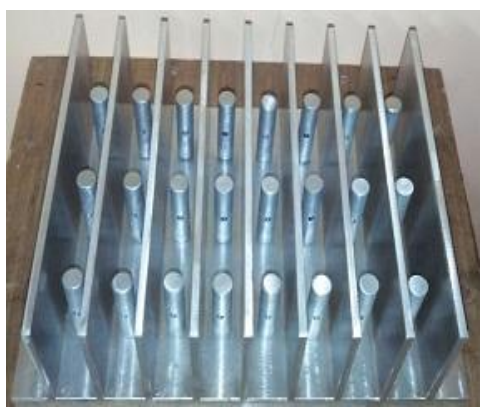

Fig.2(e) Height of pin $35 \mathrm{~mm}$ with single perforation

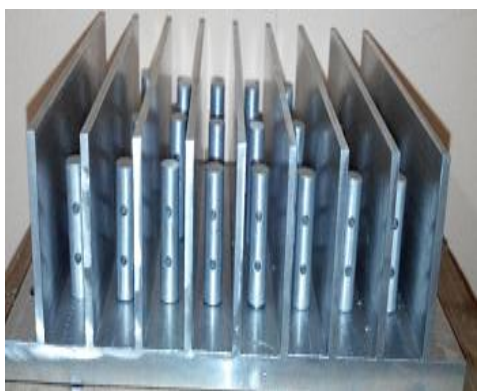

Fig.2(f) Height of pin $35 \mathrm{~mm}$ with double perforation

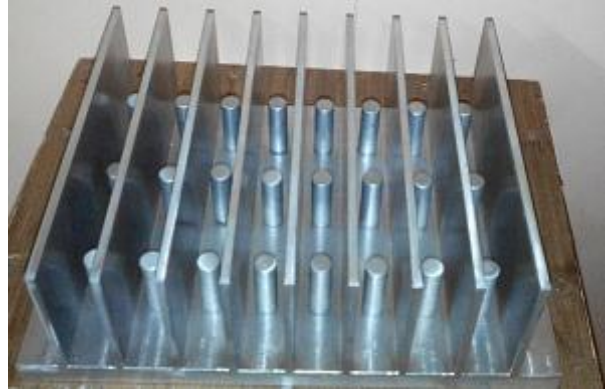

Fig.2(g) Height of pin $25 \mathrm{~mm}$ without perforation

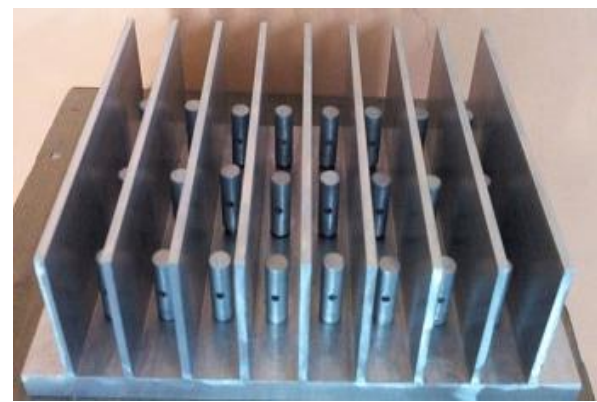

Fig.2(h) Height of pin $25 \mathrm{~mm}$ with single perforation

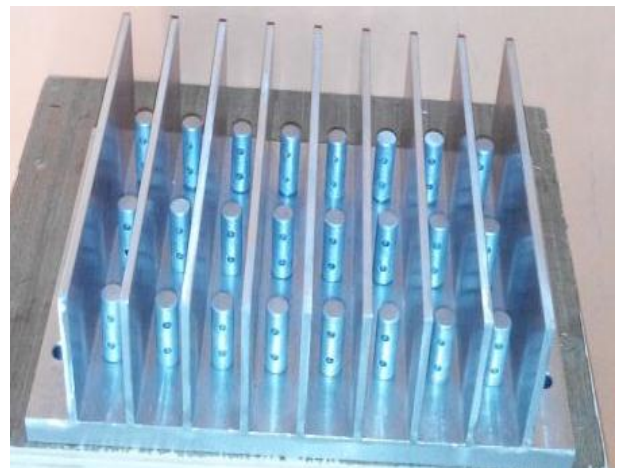

Fig.2(i) Height of pin $25 \mathrm{~mm}$ with double perforation

Fig.2 Nine parallel plate pin fin models.

Parallel plate pin fins heat sinks are the heart of experiment over which the experimental study is be done. In the experimentation for all three height solid set of pin fin are compared with single and double perforated pin fin. There are nine pin fin geometries are as shown in Fig.2.

\section{Data Reduction}

Heat input supplied to fins is given by,

$\mathrm{Q}_{\text {in }}=\mathrm{VI}$

The most of the heat lost by radiation to surrounding air which is calculated as,

$\mathrm{Q}_{\mathrm{rad}}=\varepsilon \sigma \mathrm{A}_{\mathrm{s}}\left(\mathrm{Ts}^{4}-\mathrm{Ta}^{4}\right)$

Heat lost by convection $Q_{C}=Q_{\text {in }}-Q_{\text {rad }}$

This rate of heat transfer by convection can be given by, 
$\mathrm{Q}_{\mathrm{C}}=\mathrm{h} \mathrm{A} \mathrm{A}_{\mathrm{s}}$ (Ts- Ta)

\subsection{Calculation of base and exposed area of fins}

Area of base plate $\left(\mathrm{A}_{\mathrm{bp}}\right)=\mathrm{L} \times \mathrm{W}$

Area of one plate fin $=(2 x H x L)+(2 x H x t)+(L x t)$

Area of all vertical plate fin $\left(A_{f}\right)=$ Area of one plate fin $x$ No. of fin

Area of all vertical pin fins with perforation is,

$\left(\mathrm{A}_{\mathrm{pf}}\right)=\mathrm{Nf}\left\{\frac{\pi}{4} D^{2}+(\pi \mathrm{DH})-\left(\mathrm{n} \frac{\pi}{2} d^{2}+\mathrm{n} \pi \mathrm{dD}\right)\right\}$

Total surface area $A_{s}=A_{b p}+A_{f}+A_{p f}(4)$

The mean temperature is calculated as,

$T m=\frac{T s+T a}{2}$

The average convective heat transfer coefficient is given by,

$h=\frac{\text { Nu.Kair }}{L c}$

\section{Results and Discussion}

In the experiment for three different heights, solid pin fins are compared with single and double perforated pin fin. For all nine set heat is kept constant as 20W, 40 $\mathrm{W}, 60 \mathrm{~W}, 80 \mathrm{~W}$ and $100 \mathrm{~W}$.

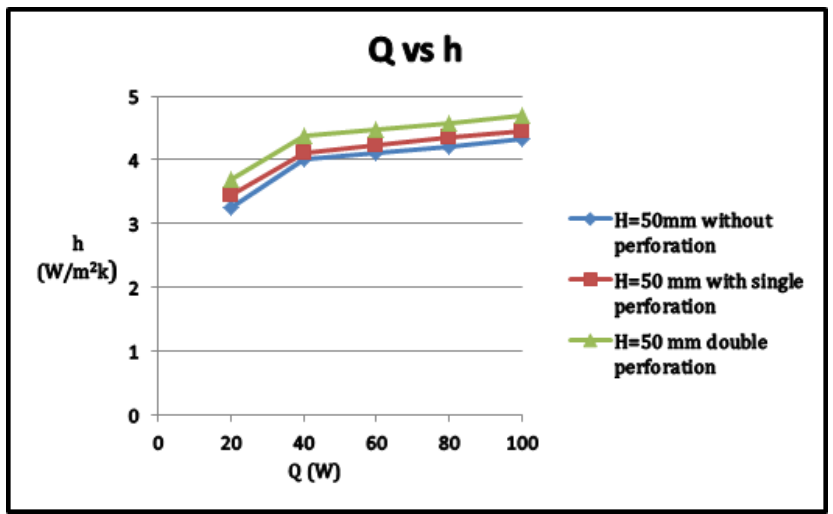

Fig.3 Variation of heat transfer coefficient vs Heat input for $50 \mathrm{~mm}$ pin fin height.

The Fig. 3 shows variation of heat transfer coefficient vs heat input for $50 \mathrm{~mm}$ pin fin height. It is observed that, double perforated pin fin has heat transfer coefficient $4.69 \mathrm{~W} / \mathrm{m}^{2} \mathrm{k}$ at $100 \mathrm{~W}$ whereas single perforated and solid pin fin has $4.44 \mathrm{~W} / \mathrm{m}^{2} \mathrm{k}, 4.33 \mathrm{~W} / \mathrm{m}^{2} \mathrm{k}$ respectively. The double perforated pin fin has higher heat transfer coefficient compared single perforated and solid pin fin.

The Fig.4 shows Variation of temperature difference vs heat input for $50 \mathrm{~mm}$ pin fin height. At $100 \mathrm{~W}$, the temperature difference value for solid pin fin is $88.2^{\circ} \mathrm{C}$ whereas for single and double perforated pin fin is $87.8^{\circ} \mathrm{C}, 85.8^{\circ} \mathrm{C}$ respectively. The lesser is the value of $\Delta \mathrm{T}$ higher is the heat transfer coefficient.

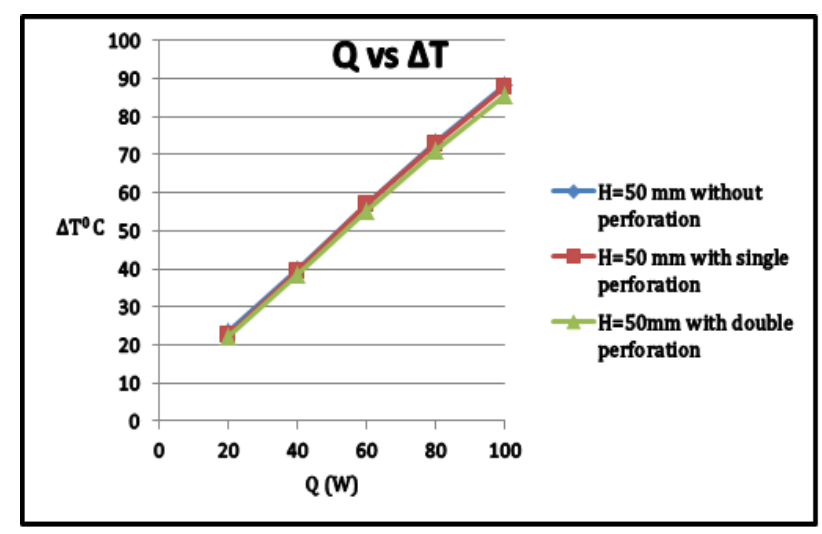

Fig.4 Variation of temperature difference vs Heat input for $50 \mathrm{~mm}$ pin fin height.

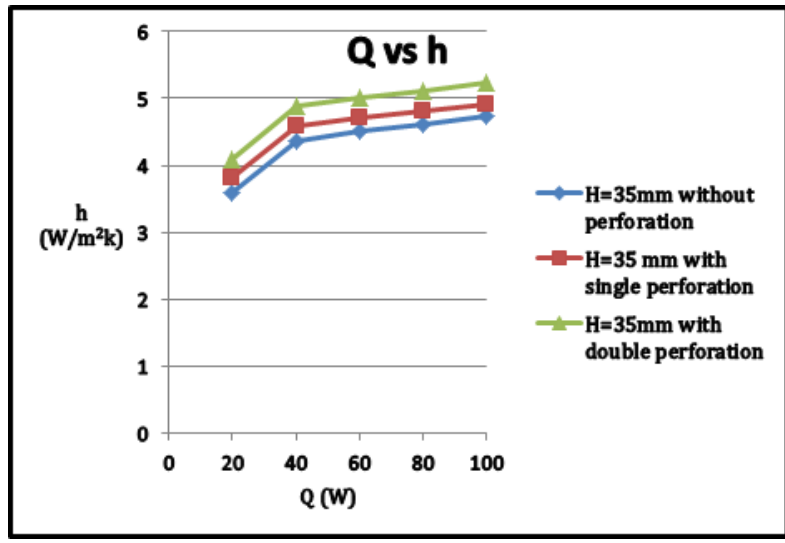

Fig.5 Variation of heat transfer coefficient vs Heat input for $35 \mathrm{~mm}$ pin fin height.

The Fig.5 shows variation of heat transfer coefficient vs heat input for $35 \mathrm{~mm}$ pin fin height. It is observed that, double perforated pin fin has heat transfer coefficient $5.23 \mathrm{~W} / \mathrm{m}^{2} \mathrm{k}$ at $100 \mathrm{~W}$ whereas perforated and solid pin fin has $4.92 \mathrm{~W} / \mathrm{m}^{2} \mathrm{k}, 4.72 \mathrm{~W} / \mathrm{m}^{2} \mathrm{k}$ respectively.

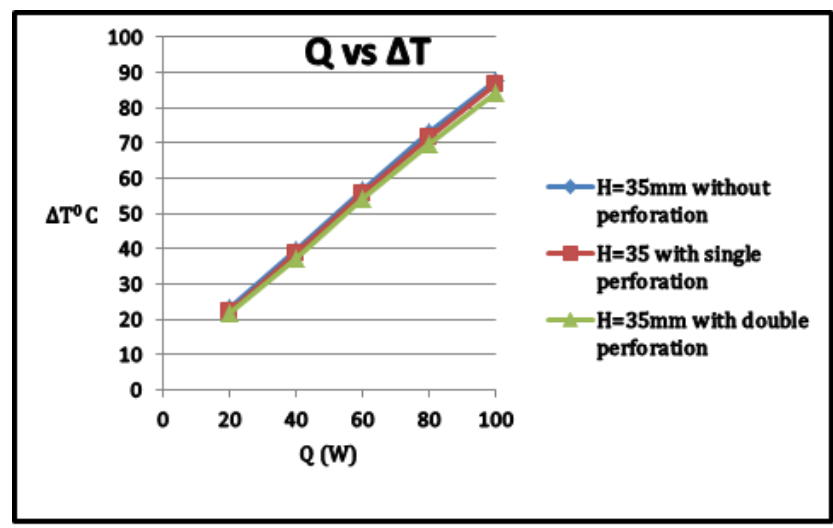

Fig.6 Variation of temperature difference vs Heat input for $35 \mathrm{~mm}$ pin fin height.

The Fig.6 shows Variation of temperature difference vs heat input for $35 \mathrm{~mm}$ pin fin height. At $100 \mathrm{~W}$, the temperature difference value for solid pin fin is $87.6^{\circ} \mathrm{C}$ whereas for single and double perforated pin fin is 
$86.4^{\circ} \mathrm{C}, 84^{\circ} \mathrm{C}$ respectively. The lesser is the value of $\Delta \mathrm{T}$ higher is the heat transfer coefficient.

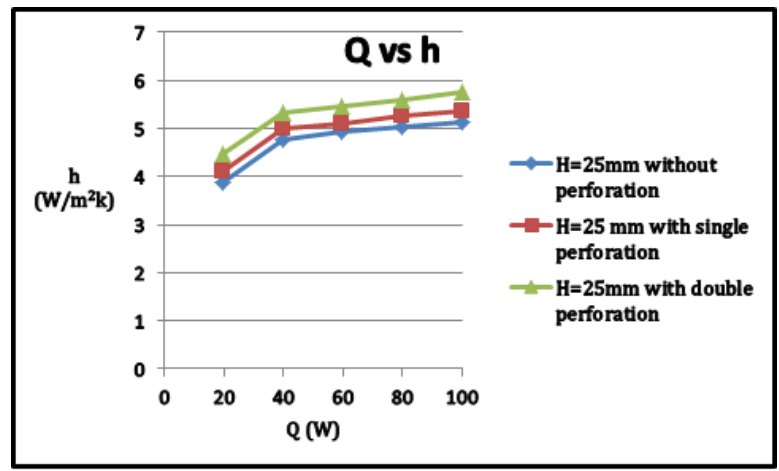

Fig.7 Variation of heat transfer coefficient vs Heat input for $25 \mathrm{~mm}$ pin fin height.

The Fig.7 shows that heat heat transfer coefficient increases with increase heat input. At $25 \mathrm{~mm}$ pin height double perforated pin fin has higher heat transfer coefficient as $5.75 \mathrm{~W} / \mathrm{m}^{2} \mathrm{k}$ compared to solid and single perforated pin fin.

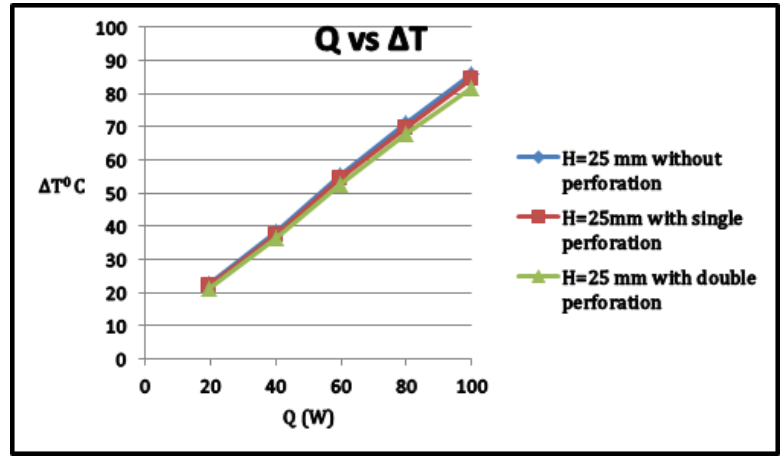

Fig.8 Variation of temperature difference vs Heat input for $25 \mathrm{~mm}$ pin fin height.

The Fig. 8 shows that temperature difference value is more in solid pin compared to single and double perforated pin fin respectively. Higher is the value of temperature difference lesser is the heat transfer coefficient. At 100W solid pin fin has temperature difference value $85.8^{\circ} \mathrm{C}$ whereas single and double perforated pin fin has $84.4^{\circ} \mathrm{C}, 81.6^{\circ} \mathrm{C}$ respectively. The less value of $\Delta \mathrm{T}$ is observed for smaller pin fin height i.e. at $25 \mathrm{~mm}$. The value of $\Delta \mathrm{T}$ along the height of pin goes on rising and decreases the heat transfer performance.

From the fig. 9 it is observed that, $25 \mathrm{~mm}$ pin fin height gives higher heat transfer coefficient compared to $35 \mathrm{~mm}$ and $50 \mathrm{~mm}$ pin fin height.

From the Fig. 10 it is observed that, $25 \mathrm{~mm}$ pin fin height with single perforation gives higher heat transfer coefficient compared to $35 \mathrm{~mm}$ and $50 \mathrm{~mm}$ pin fin height.

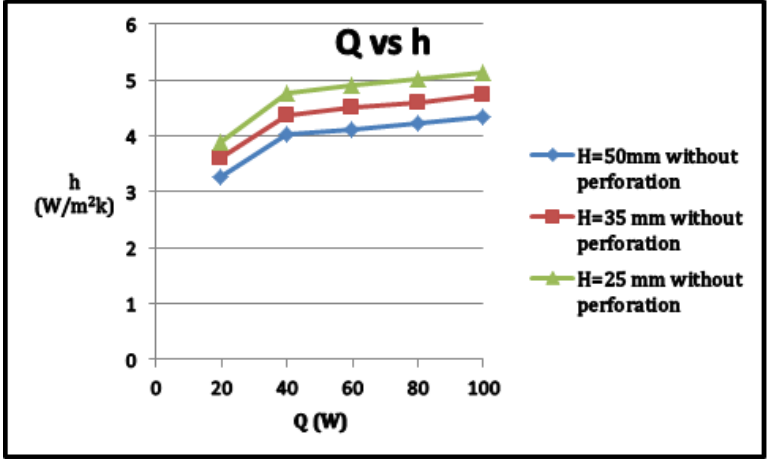

Fig.9 Variation of heat transfer coefficient vs Heat input for different pin fin height without perforation.

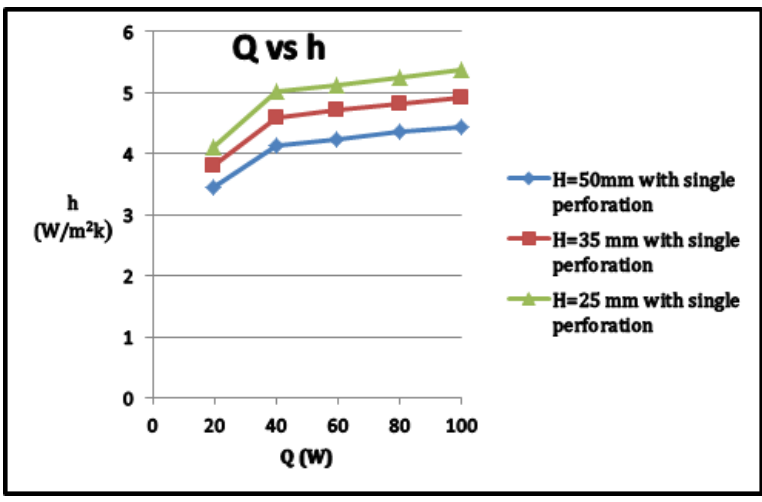

Fig.10 Variation of heat transfer coefficient vs Heat input for different pin fin height with single perforation.

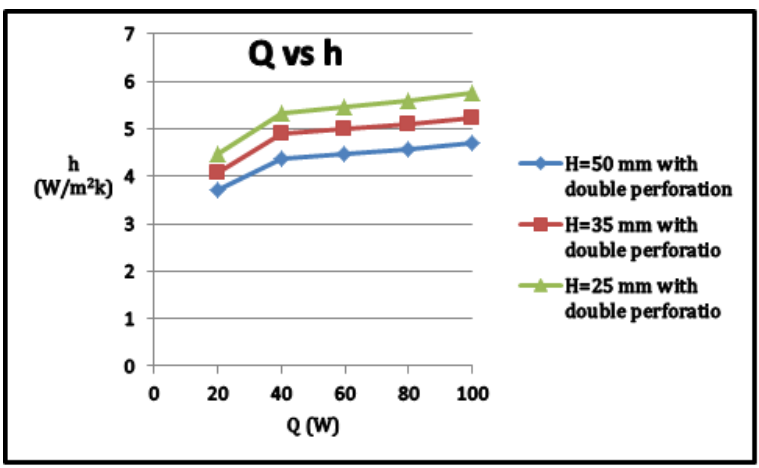

Fig.11 Variation of heat transfer coefficient vs Heat input for different pin fin height with double perforation.

From the Fig.11 it is observed that, $25 \mathrm{~mm}$ pin fin height with double perforation gives higher heat transfer coefficient compared to $35 \mathrm{~mm}$ and $50 \mathrm{~mm}$ pin fin height.

\section{Conclusions}

1) From experimental study, it is concluded that for all three pin fin height the parallel plate heat sink with perforated circular pin fin gives more heat transfer rate than solid circular pin fin. 
2) Average heat transfer coefficient for double perforations is higher than solid, single perforation respectively. The heat transfer rate increases with increase in number of perforation.

3) Out of three different pin heights, it is observed that the heat transfer coefficient is maximum for $25 \mathrm{~mm}$ and minimum for $50 \mathrm{~mm}$ pin height.

4) As lesser is the value of temperature difference higher is the heat transfer coefficient. The temperature difference is less for $25 \mathrm{~mm}$ pin fin height compared to $35 \mathrm{~mm}$ and $50 \mathrm{~mm}$ respectively.

5) The temperature difference for double perforated pin fin is very less than solid and single perforated pin fin.

\section{Nomenclature}

- $\quad \mathrm{L}=$ Length of fin $(\mathrm{m})$

- $\quad \mathrm{W}=$ Width of fin $(\mathrm{m})$

- $\mathrm{T}=$ Thickness of fin (mm)

- $\quad \mathrm{Nf}=$ Total number of pin fin

- $\mathrm{D}=$ Diameter of circular pin(mm)

- $\mathrm{H}=$ Height of fin (mm)

- $\mathrm{d}=$ Perforation diameter $(\mathrm{mm})$

- $\mathrm{n}=$ Number of perforation

- $\mathrm{Nu}=$ Nussult number

- Kair= Thermal conductivity of air $(\mathrm{W} / \mathrm{mk})$

- $\quad \mathrm{Lc}=$ Characteristic length.(mm)

- $\mathrm{h}=$ Heat transfer coefficient. $\left(\mathrm{W} / \mathrm{m}^{2} \mathrm{k}\right)$

- $\mathrm{Q}_{\text {in }}=$ Heat input to the plate pin fin-array assembly (W)

- $\quad \mathrm{Q}_{\mathrm{rad}}=$ Heat lost by radiation $(\mathrm{W})$

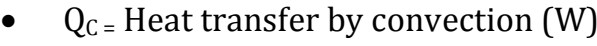

- $\varepsilon=$ Emissivity

- $\mathrm{A}_{\mathrm{bp}}=$ Area of base plate $\left(\mathrm{m}^{2}\right)$

- $\mathrm{A}_{\mathrm{f}}=$ Area of plate fin $\left(\mathrm{m}^{2}\right)$

- $\mathrm{A}_{\mathrm{pf}}=$ Area of pin fin $\left(\mathrm{m}^{2}\right)$

- $\mathrm{A}_{\mathrm{s}}=$ Total surface area of plate pin fin. $\left(\mathrm{m}^{2}\right)$

- $\sigma=$ Stefan Boltzman constant $\left(\mathrm{W} / \mathrm{m}^{2} \mathrm{k}^{4}\right)$

- $\mathrm{Ts}=$ Average surface temperature of base plate $\left({ }^{\circ} \mathrm{C}\right)$

- $\mathrm{Ta}=$ Ambient temperature $\left({ }^{\circ} \mathrm{C}\right)$

- $\mathrm{Tm}=$ Mean temperature $\left({ }^{\circ} \mathrm{C}\right)$

- $\Delta \mathrm{T}=$ Temperature difference $\left({ }^{\circ} \mathrm{C}\right)$

\section{References}

Dong-Kwon Kim, Sung Jin Kim, Jin-Kwon Bae, (2009), Comparison of thermal performances of plate-fin and pinfin heat sinks subject to an impinging flow, International Journal of Heat and Mass Transfer 52, pp. 3510-3517.

Abdullah H. AlEssa, Ayman M. Maqableh and Shatha Ammourah, (2009), Enhancement of natural convection heat transfer from a fin by rectangular perforations with aspect ratio of two", International Journal of Physical Sciences, volume 4 (10), pp. 540-547.

E.A.M. Elshafei, (2010), Natural convection heat transfer from a heat sink with hollow/perforated circular pin fins, Energy 35, pp. 2870-2877.

Monoj Baruah, Anupam Dewan and P. Mahanta, (2011), performance of elliptical pin fin heat exchanger with three elliptical perforations", ISSR Journals, Volume 3 (2), pp. 6570.

Anupam Dewan, Rajesh Kumar Shukla, (2011), computation of turbulent convective heat transfer in a hollow cirular pin fin heat exchanger", Proceedings of the 21st National and $10^{\text {th }}$ ISHMT-ASME Heat and Mass Transfer Conference, IIT Madras, India.

Ji-Jinn Foo, Shung-Yuh Pui, Yin-Ling Lai, Swee-Boon Chin, (2012), Forced convective heat transfer enhancement with perforated pin fins subject to an impinging flow , SEGi Review, volume 5, number 1, pp. 29-40.

G.Ganesh Kumar, (2013), Comparative studies on conjugate mixed convection in perforated fins, International Journal of Science and Research, pp. 2319-7064.

Ali Shakir Baqir, Ahmed Qasim, Anmar Adnan, (2014), Experimental study for staggered perforated array of pins like fins in a rectangular air cross flow", The Iraqi Journal For Mechanical And Material Engineering, volume 14, number 2, pp. 261-275.

Saurabh D.Bahadur. and G.D. Gosavi, (2014), Enhancement of natural convection heat transfer from perforated fin", International Journal of Engineering Research, volume 3, issue 9, pp. 531-535.

Murtadha Ahmed and Abdul Jabbar N. Khalifa, (2014), Natural convection heat transfer from a heat sink with fins of different configuration" International Journal of Innovation and Applied Studies, volume 9, number 3 , pp. 1043-1047.

Vishvas S. Choure, Mahesh R. Jagadale, Vijay W. Bhatkar, (2015), Heat transfer enhancement using perforated pin Fins, International Journal For Technological Research In Engineering ,volume 3, issue 2, pp. 2347 - 4718. 